\title{
Увеличение длины распространения поверхностных плазмон-поляритонов методами мезоразмерной фотоники
}

\author{
В.Н. Кручинин ${ }^{1)}$, С.В. Рыхлицкий ${ }^{1)}$, М.В. Кручинина ${ }^{2)}$, Г.В. Шувалов ${ }^{2)}$, И.В. Минин ${ }^{2)}$, О.В. Минин ${ }^{2)}$ \\ ${ }^{1}$ Институт физики полупроводников им. А.В. Ржанова СО РАН, \\ Новосибирск, 630090, пр. Ак. Лаврентьева, 13 \\ ${ }^{2}$ Сибирский государственный ордена Трудового Красного Знамени институт метрологии, \\ Новосибирск, 630004, ул. Димитрова, 4 \\ тел:+7 (383) 330-8946, факс:+7 (383) 333-2771, эл. почта: kruch@isp.nsc.ru
}

DOI 10.34077/RCSP2019-145

Производительность современных вычислительных систем ограничивается, главным образом, скоростью обмена данными между ядрами. Один из путей увеличения быстродействия компьютеров заключается в переходе от электроники к фотонике, а точнее, к нанофотонике. Однако, уменьшение размеров фотонных компонентов в субмикронную область затруднено из-за необходимости преодоления дифракционного предела. Эту фундаментальную проблему можно решить переходом от объемных волн к поверхностным волнам, так называемым поверхностным плазмон-поляритонам (ППП), распространение которых основано на процессах взаимодействия электромагнитного излучения и электронов зоны проводимости вблизи металлических поверхностей. Это позволяет превзойти дифракционный предел классической оптики и работать в оптическом ближнем поле с субволновыми размерами, создавая нанометровые устройства ( 10 нм), одновременно обладающих высоким быстродействием ( 10 ТГц).

Основной проблемой, затрудняющей создание приборов, использующих ППП, является сильное поглощение последних металлической средой. В настоящее время создано несколько устройств, позволяющих управлять распространением ППП. Описаны призмы, 3D диэлектрические кубоиды и полусферы, которые могут работать в режиме «на отражение» [1, 2]. Кроме того, в работе [3] была описана структура, которая может быть использована в качестве волновода путем создания простой периодической матрицы 3D диэлектрических прямоугольных параллелепипедов, разделенных воздушным промежутком.

На основе упомянутых выше работ, разработан плазмонный волновод, состоящий из периодически расположенных на алюминиевой подложке 3D диэлектрических кубоидов на поверхности металлической пленки, возбуждаемых ППП [4]. Такой волновод способен почти вдвое увеличить расстояние распространения ППП волн на телекоммуникационной длине волны $\lambda_{0}=1550$ нм (здесь $\lambda_{0}$ - длина волны в свободном пространстве, $\lambda_{0}>\lambda_{\text {spp }}$ ) по сравнению с подложкой без кубоидов. Структура представляла собой периодически размещенные 6 прямоугольных параллелепипедов с воздушным промежутком между ними. Изучены характеристики нового типа плазмонного волновода в условиях, когда высота кубоидов изменялась от $0,05 \lambda_{0}$ до $0.16 \lambda_{0}$ при различных расстояниях между кубоидами. Было показано, что наилучшие характеристики с точки

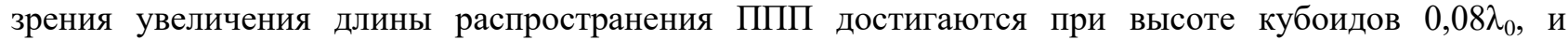
расстоянии между ними $2,5 \lambda_{0}$. В этом случае расстояние распространения ППП может быть увеличено не менее, чем вдвое. Кроме того, показано, что в этом случае обеспечивается субволновая фокусировка вблизи теневой поверхности всех прямоугольных параллелепипедов. Фактически, каждый диэлектрический кубоид в данном случае представлял собой пассивный ретранслятор усилитель ППП. Увеличение расстояния распространения ППП вдвое пассивными средствами открывает широкие перспективы использования оптоэлектронных процессоров: от суперкомпьютеров до компактных электронных устройств [5].

\section{Лuтература}

[1] И.В. Минин, О.В. Минин // Вестник НГУ. Серия: Информационные технологии. 2014. Т.12. вып.4. С.59-70.

[2] I.V. Minin, O.V. Minin, V. Pacheco-Pena, M. Beruete // Opt. Lett. 2015. V.40. P.2329-2332.

[3] I.V. Minin, O.V. Minin, V. Pacheco-Pena, M. Beruete // Appl. Phys. Lett. 2015. P. 254102(6).

[4] V. Pacheco-Pena, I.V. Minin, O.V. Minin, M. Beruete // Photonics. 2016. V.3. N.1. P.10-14.

[5] I.V. Minin and O.V. Minin. Diffractive Optics and Nanophotonics: Resolution Below the Diffraction Limit. London: Springer, 2016. 457 p. 